\title{
Parenthood and Later Life Health: An International Life Course Analysis of Parents and Childless Adults Aged 50 and Older
}

\author{
Nadine Reibling* and Katja Möhring**
}

\begin{abstract}
This study investigates how women's and men's fertility history affect their health in later life and if this relationship varies across countries and cohorts. We use life history data and current health status of persons aged 50 and over from the Survey of Health, Ageing and Retirement in Europe (SHARE) for 13 countries. Country-fixed effects regressions show that parenthood itself and the number of children have little impact on later life health, but fertility timing is important. Moreover, significant country and cohort differences show that the health implications of timing depend upon the socio-historic context.
\end{abstract}

Keywords: parenthood, health, life course, SHARELIFE, welfare state

\section{Elternschaft und Gesundheit im höheren Lebensalter: Eine internationale Lebenslaufanalyse von Eltern und kinderlosen Erwachsenen im Alter 50+}

Zusammenfassung: Der Beitrag untersucht, wie sich die Elternschaft auf die Gesundheit von Männern und Frauen im höheren Alter auswirkt und ob sich der Zusammenhang zwischen Elternschaft und Gesundheit für verschiedene Länder und Geburtskohorten unterscheidet. Die Studie verwendet Lebenslauf- und Gesundheitsdaten für Personen im Alter 50+ aus dem Survey of Health, Ageing and Retirement in Europe (SHARE). Fixed-effects-Regressionen für 13 Länder zeigen, dass die Elternschaft und die Anzahl der Kinder geringen Einfluss auf die Gesundheit im höheren Alter haben, der Zeitpunkt der ersten Elternschaft aber bedeutsam ist. Signifikante Länder- und Kohortenunterschiede zeigen, dass die Bedeutung des Zeitpunkts vom jeweiligen sozio-historischen Kontext abhängt.

Schlüsselwörter: Elternschaft, Gesundheit, Lebenslauf, SHARELIFE, Wohlfahrtsstaat

\section{Parentalité et santé à un âge avancé : une analyse internationale des parents et des personnes sans enfants à âgés de $\mathbf{5 0}$ ans et plus}

Résumé: Cet article examine comment la parentalité influence la santé des femmes et des hommes à un âge avancé et si cette relation diffère selon les pays et les cohortes de naissance. Cette étude utilise des données biographiques et des informations sanitaires issues de l'enquête SHARE, portant sur des personnes de 50 ans et plus. Des régressions fixed-effects pour 13 pays indiquent que la parentalité et le nombre d'enfants ont peu d'influence sur la santé à un âge avancé, mais que l'âge à la naissance est important. Des différences significatives entre pays et cohortes indiquent en outre que l'importance de l'âge à la naissance dépend du contexte social et historique.

Mot-clés: parentalité, santé, parcours de vie, SHARELIFE, État-providence

Department of Social Sciences, Siegen University, D-57068 Siegen,

reibling@soziologie.uni-siegen.de.

** School of Social Sciences, University of Mannheim, D-68131 Mannheim,

moehring@uni-mannheim.de. 


\section{Introduction ${ }^{1}$}

An increasing number of studies aims to link family and health trajectories in a life course framework (Mayer 2009). This rising effort strives both from a growing interest in the sociology of health to identify early-life predictors of non-communicable diseases/mortality (Burton-Jeangros et al. 2015) and in family sociology to understand the consequences of family transitions and their timing (Nauck et al. 2009). Moreover, investigating family trajectories can help to enlighten the distal causes of social disparities in health, since partnership and parenthood are, for instance, strongly associated with one's socioeconomic development over the life course (Furstenberg Jr. et al. 1987; Taylor 2009).

Becoming a parent is one of the most fundamental and transformative life course transitions. As a biological event, pregnancy and childbirth can have direct consequences for the health of mothers. However, it also affects various dimensions of social life including labor force participation, socio-economic development, marital quality, gender equality, leisure activities and social integration which are important determinants of physical and mental health for both men and women (indirect effects). As a result, there has been a multidisciplinary interest in the analysis of how becoming and being a parent affects individual's health.

The changing fertility behaviour during the second half of the $20^{\text {th }}$ century with a decreasing number of children per couple and a rising age of mothers and fathers at first birth has further fuelled the debate on the health consequences of parenthood. The total fertility rate dropped in the United States from 2.48 in 1970 to 2.04 in 2003 and decreased even further in many European countries, e. g., in Spain from 2.88 in 1970 to 1.27 in 2003 . The percent of births to women aged 40 and older doubled during that period, for instance, in the US, Denmark, and Sweden. And in all countries the share of first and second births among the age group 40 and older has increased substantially (Billari et al. 2007). Clinicians express strong concerns over the health consequences of delayed childbearing (Breart 1997; Ben-David et al. 2016) which fuel the public debate of this issue.

While all advanced, industrialized nations share these demographic trends, there are still marked differences in the fertility rate and timing of parenthood across countries. Moreover, welfare states offer different contexts for parenthood: Nordic welfare states, for instance, provide strong support for families through generous parental leave and public childcare, while in other regions, such as Southern Europe, the welfare states provide less help to families' care-taking responsibilities. Comparing the effects of parenthood on health across studies from different countries

$1 \quad$ Nadine Reibling received funding for this article as a member of the HiNEWS project - Health Inequalities in European Welfare States - funded by NORFACE (New Opportunities for Research Funding Agency Cooperation in Europe) Welfare State Futures programme (grant reference: 42-14-110). For more details on NORFACE, see http://www.norface.net/11. 
suggests that institutional contexts may not only shape fertility behaviour, but also influence how parenthood affects parents' health.

Considering the potential significance of both demographic trends and institutional contexts, this paper investigates life course effects of parenthood for health across countries and cohorts. We use life history data and health status information from the Survey of Health, Ageing and Retirement in Europe (SHARE) for 13 European countries. The analysis group comprises women and men older than 50 years. Based on country-fixed-effects regressions, we compare parenthood effects across three health measures: depressive feelings, self-rated health status, and the number of chronic diseases.

\section{Theory}

The advent of parenthood defines a core transition in the life course that may catalyse and interlock sets of social and biological consequences. The timing of that transition implicitly gauges how smoothly the social and biological spheres come together, with lifelong consequences for health. (Mirowsky 2002, 340)

We start by reviewing theories that have been developed for explaining the link between the fertility history and health. These theories not only make predictions regarding the overall effect of parenthood on health, but also consider the health consequences of parity, i. e. number of children, and their timing. Three strands of theoretical mechanisms can be identified in this body of literature: biological explanations, social mechanisms, and selection processes.

\subsection{Biological explanations}

Evolutionary and developmental frameworks suggest direct biological effects of parenthood for the physical health of mothers. The disposable soma theory argues that there is a "trade-off between longevity and reproduction," because reproduction uses resources that would have otherwise been available to the somatic maintenance of the mother's body (Westendorp and Kirkwood 1998). Thus, this framework suggests that mothers are in worse health than childless women and that this health disadvantage increase with the number of pregnancies women have. Empirical support for this perspective can be found in the fact that both in historic (Westendorp and Kirkwood 1998) and in recent cohorts (Hurt et al. 2006), a very high number of children is associated with increased mortality.

Biological arguments have also been important in the literature on fertility timing, because there is a biological fertility limit that ranges for women from around 16 to the early 40s. Therefore, a developmental perspective suggests that the "optimum age at first birth [is] shortly after the reproductive system is ready, 
while the organism enjoys the energy and resilience of youth" (Mirowsky 2005, 32). Clinicians are concerned about teenage births, because they often occur prior to the complete development of the reproductive system and are therefore associated with a higher risk for complications and health risks for mothers and children (Ozalp et al. 2003). However, the primary concern of bio-medical frameworks have been the health risks for mothers and children arising from late childbearing such as birth defects, stillbirths, and maternal morbidity and mortality (Kozuki et al. 2013; Restrepo-Méndez et al. 2015; Lisonkova et al., 2017). Older mothers are also more likely to receive intensive medical interventions such as caesarean deliveries (Ben-David et al. 2016).

However, clinical research has also highlighted health advantages of motherhood particularly the long-term protection against breast cancer that arises from multiple and early births (Russo et al. 2005). On the other hand, motherhood and higher parity have also been shown to increase the risk for other cancer types (Muñoz et al. 2002).

In sum, biological explanations suggest mostly direct negative effects for mothers' physical health. These negative effects should be more pronounced the more children a woman has and if births occur either too early or too late.

\subsection{Social mechanisms}

Social scientists have stressed the various social correlates of parenthood which can exhibit positive or negative indirect effects on mothers' and fathers' health. Unlike biological frameworks, social scientists also consider implications for parents' mental health. On the one hand, parenthood can be viewed as a beneficial transition (role accumulation/enhancement) (Sieber 1974; Marks 1977) that provides meaning to one's life, increases social integration and responsibility towards one's own health. For instance, parents are less likely to engage in risk behaviour (Arnett 1998). On the other hand, parenthood can lead to role strain (Goode 1960) which creates stress and promotes unhealthy behaviour such as low physical activity, less sleep, and worse dietary habits (Nomaguchi and Bianchi 2004).

Later life health might to some extent also reflect the costs and benefits that adult children have for parents (Umberson et al. 2010). The relative importance of current effect of children and accumulated life course influences of parenthood also depend on the dimension of health. For instance, physical health (e. g., the development of chronic conditions such as heart disease) will reflect more strongly long-term strains and resources associated with parenthood.

Since parenthood can entail benefits as well as strains, research has highlighted the importance of timing. Early parenthood can lead to a process of cumulative disadvantage (DiPrete and Eirich 2006), because young parents are more likely to experience a disadvantaged socio-economic development and more disruptive partnerships (Taylor 2009). Therefore, in contrast to bio-clinical research, social 
scientists see delaying childbirth as beneficial for mothers' and fathers' health (Lacey et al. 2017), because at a later age individuals have acquired educational, financial, and social resources that help them to cope with the costs and stresses of parenthood.

There has been a debate to what extent there is a limit to the benefits of delaying childbirth. Some theorists suggest that from a resource perspective delaying as long as possible is beneficial (Mirowsky 2005). Others have argued that such a limit might exist particularly for women. If women have births later than social norms expect or later than they personally envisioned, this can create psycho-social stress with negative implications for their health (Carlson 2011). Psycho-social stress is particularly likely if late childbearing reflects experienced difficulties with conception.

In sum, social mechanisms suggest that parenthood can be good for parents' health if the benefits outweigh the costs and that this is more likely with lower parity and delayed childbearing. Unlike the biological explanations, the indirect effects postulated by social mechanisms also suggest an impact of fatherhood on health. While delaying childbirth is expected to be generally beneficial for men, there may be a limit to the benefits of late childbirth for women if they feel that they had their children too late considering the present normative expectations or their own life plans.

\subsection{Selection}

There are also a variety of selection processes that may affect the relationship between parenthood and health in later life. First, health selection could affect whether persons become parents, but also parity and timing so that potentially the effect of all three characteristics on later life health is underestimated. Parents could be a healthier group than childless persons, since healthier women are more likely to marry and have children (Brockmann and Klein 2004). Parents with more children could be healthier than parents with less children, since biological fertility is associated with health. Finally, older mothers/fathers could be a healthier group than younger mothers/fathers, because they are still able to conceive at an age where other men and women have reached the end of fecundity (Yi and Vaupel 2004). The significance of the health selection effect is seen as important in historic populations (Hurt et al. 2006). In contemporary samples they are seen as less relevant (Huijts et al. 2013), because fertility is stronger determined by social factors since it can be controlled via contraceptives (Hurt et al. 2006). Second, social selection processes can affect fertility. Men and women with a higher socioeconomic status face higher opportunity costs and might thus more often be childless or have less children. Moreover, a low socioeconomic status seems to increase the likelihood of an early birth.

In sum, selection mechanisms could lead to an overestimation of the negative consequences of childlessness and early age at first birth for later life health, while the costs of higher parity and late age at birth for later life health might be underestimated. 


\section{Empirical evidence}

In the following part, we review the empirical evidence on the relationship between characteristics of the fertility history and health outcomes.

\subsection{Parenthood}

Studies on the general effect of parenthood on health find either no health differences between parents and childless persons (Eggebeen and Knoester 2001; Mirowsky 2005; Teachman 2010; Kroll et al. 2016) or a health advantage for parents on a variety of health outcomes (Grundy and Tomassini 2005; Kohler et al. 2005; Helbig et al. 2006; Hurt et al. 2006; Teachman 2010; Read et al. 2011; Gibney et al. 2015). Interestingly, this is in contrast to research on happiness and life satisfaction which usually finds that parents with resident children are unhappier than childless persons (Hansen 2012). Age at first birth (Mirowsky 2005) and marital status (Nomaguchi and Milkie 2003) are important moderators of the effect of parenthood on health. Moreover, the effect of parenthood/childlessness seems to vary cross-nationally (Huijts et al. 2013; Tanaka and Johnson 2014).

\subsection{Parity}

There is mixed evidence concerning the implications of the number of births for health. While a number of studies find excess mortality (Hurt et al. 2006) and worse health for parents with a higher number of children (Kington et al. 1997; Kohler et al. 2005; Read et al. 2011), others find no associations (Henretta 2007; Spence 2008). Comparative studies show interesting - albeit contradictory - variations across contexts. In a three country comparison, Grundy (2009) reports that higher parity is associated with higher mortality in England/Wales and the US, but lower mortality in Norway. She suggests that the availability of public childcare might lead to the health benefits in Norway. In contrast, Hank's (2010) comparison of East and West German women finds that in West Germany higher parity is related to better health, while higher parous East German women have worse health in later life, even though childcare was widely available in the Eastern, but not in the Western part of Germany.

\subsection{Early age at first birth}

A large number of studies confirms that early childbearing is associated with poorer physical (Kington et al. 1997; Mirowsky 2002; Mirowsky 2005; Henretta 2007; Spence 2008; Taylor 2009; Barban 2013; O’Flaherty et al. 2015) and mental health for mothers (Mirowsky and Ross 2002; Spence 2008; Carlson 2011; Read and Grundy 2011). The evidence base for fathers is smaller. Most Anglo-Saxon studies also suggest negative health implications of early births for men (Mirowsky 2002; 
Mirowsky and Ross 2002; Grundy and Tomassini 2005; O'Flaherty et al. 2015) while a study based on German data finds no effects of timing for fathers (Hank 2010).

\subsection{Late age at first birth}

The health effects of late childbearing are more controversial. For mothers, late age at first births is associated with a higher risk for breast cancer (Merrill et al. 2005), health limitations (Read et al. 2011), and sometimes a poorer physical (Mirowsky 2002; Mirowsky 2005) and mental health (Mirowsky and Ross 2002; Spence 2008; Carlson 2011). However, late births neither have a negative effect on overall mortality (Mirowsky 2005; Henretta 2007; Grundy 2009) nor on the likelihood to have (any) cancer (Henretta 2007). Late childbearing can even decrease the risks for certain cancers such as endometrial and cervical cancer (Merrill et al. 2005). For fathers, a late age at birth is either not associated with health (Hank 2010) or seems to convey health benefits (Mirowsky 2002; Mirowsky 2005; Mirowsky and Ross 2002).

The health implications of parenthood have been studied quite extensively. However, the existing evidence base is ambiguous with respect to several characteristics except the negative consequences of early births. Only a small number of studies have also considered fathers. Reviewing the evidence already suggests that the parenthood effects on health might not be universal, but depend upon the historical or social context. This is why the aim of this study is to systematically compare the later life consequences of parenthood across cohorts and countries.

\section{$4 \quad$ Institutional and historical context}

\subsection{The 1920 to 1959 birth cohorts}

The cohorts to be examined in this study are born between 1920 and 1959 . They cover an interesting period of fertility trends in Europe: About half of our sample consists of pre-WWII cohorts and the other half was born after the war. The youngest cohort reached adolescence right before WWII. In our sample, less than $1 \%$ of the births occurred before or during the war. Thus, this study analyses primarily post-WWII fertility patterns occurring mostly between 1950 and 1980. The earlier cohorts from 1920 to 1944 are the parents of the baby boom generation. They display a higher fertility and a lower age at first birth than previous cohorts. For instance, in Austria the total fertility rate was 2.4 in 1950 compared to 1.96 in 1930, in France 2.93 in 1950 compared to 2.27 in 1930, and in Denmark 2.58 compared to 2.30 in 1930 (Tomka 2013). The later cohorts who reached adolescence not before the $1960 \mathrm{~s}$ already exhibit part of the demographic change towards lower and later fertility in the Western countries that continued into the $21^{\text {st }}$ century. 


\subsection{Implications of the social-historical context}

The majority of existing work on parenthood and later life health comes from single-country studies. However, comparing the results across studies from different countries (Hansen 2012) and recent comparative work (Grundy 2009; Hank 2010; Huijts et al. 2013; Gibney et al. 2015) suggests that the wider social context could affect how parenthood and its timing affects later life health. Thus, scholars have become increasingly interested in exploring the "historical, cultural and social variations" in the relationship between parenthood and health (Mirowsky and Ross $2002,1293)$. This interest strongly relates to the comparative health inequalities literature which has investigated how contextual factors such as the institutional arrangement of the welfare state moderates social influences on health (Bambra 2006; Beckfield et al. 2015). With respect to parenthood, we argue that the social context could moderate both the biological and the social mechanisms that link parenthood and health.

First, while the biological consequences of parenthood are based on physiological processes, the social context can affect the likelihood of certain risks as well as their impact on health. For instance, better nutrition and living standards have contributed to a reduction in maternal mortality (Scalone 2014). Even more important was the progress in the safety of maternal care for the decreasing biological risks of pregnancy and childbirth (Loudon 2000). The establishment of universal healthcare systems in European countries strongly increased the access to maternity care (Kennedy et al. 2015). Since both living standards and access to maternity care substantially improved in the second half of the $20^{\text {th }}$ century, we can expect that parenthood, higher parity, and early or late age at first birth have been less detrimental to later life health in the younger than in the older cohorts.

Second, the social context might also affect the social costs and benefits that parenthood entails. A number of scholars have suggested that welfare states, particularly transfers and services provided to families, might increase the benefits and reduce the costs of parenthood (Curtis and Phipps 2004; Aassve et al. 2005; Aitken et al. 2015). This might be especially true for women, for whom family policy also suggests independence from their partner and "the capacity to form and maintain an autonomous household" (Orloff 1993, 319; original was in italics). This could be especially important for younger mothers who are more likely to have extra-marital births (Taylor 2009). Thus, we expect that countries with more generous family policy and services, i. e. that provide more public care services and more generous parental leave arrangements, such as Scandinavian and Eastern European welfare states, should show more positive effects of parenthood and less negative effects of early childbirth than regimes that mostly rely on family support such as conservative and Mediterranean welfare states. 


\subsection{Hypotheses}

This study tests the following hypotheses: (1) childless individuals are in worse health than parents (Parenthood), (2) a higher number of children is associated with worse health for mothers and less so for fathers (Parity), (3) early parenthood is detrimental to parents' health (Timing-Early), (4) for mothers, health improves with increasing age at childbirth until a certain age and then declines, while fathers' health continuously improves with delaying childbirth (Timing-Late), (5) the parenthood characteristics are most strongly associated with chronic conditions which incorporates experiences over a long period of time and least with depression which can change more quickly based on current life circumstances (Health-Outcomes), (6) negative effects of higher parity and young age at first birth are smaller in younger cohorts (Cohort), and (7) negative effects of higher parity and lower age at first birth are smaller in welfare states with more generous family policy and services (Scandinavia $<$ Eastern $<$ Continental $<$ Southern) (Country).

\section{Data, operationalization, and methods}

\subsection{Data}

The empirical analysis is based on data from the Survey of Health, Ageing and Retirement in Europe (SHARE) waves 4 (2010, Release 1.1.1) and 5 (2013, Release 1.0.0) and information on the marital, fertility, and employment history from SHARELIFE (wave 3, 2008/2009, Release 1) (Schröder 2011; Börsch-Supan et al. 2013). ${ }^{2}$ Health information and the control variables are drawn from wave 4 and wave 5 for those who did not participate in wave 4 and combined with the life history information from wave 3. The analysis sample consists of 5577 men and 6242 women who were older than 50 years at the time of the interview for SHARELIFE, hence born in 1920 to 1959 . The sample comprises the 13 countries Austria, Belgium, Czech Republic, Denmark, France, East Germany, West Germany, Italy, The Netherlands, Poland, Spain, Sweden and Switzerland.

2 This paper uses data from SHARE Waves 1, 2, 3 (SHARELIFE), 4 and 5 (DOIs: 10.6103/ SHARE.w1.500, 10.6103/SHARE.w2.500, 10.6103/SHARE.w3.500, 10.6103/SHARE. w4.500, 10.6103/SHARE.w5.500), see Börsch-Supan et al. (2013) for methodological details. The SHARE data collection has been primarily funded by the European Commission through FP5 (QLK6-CT-2001-00360), FP6 (SHARE-I3: RII-CT-2006-062193, COMPARE: CIT5CT-2005-028857, SHARELIFE: CIT4-CT-2006-028812) and FP7 (SHARE-PREP: N²11909, SHARE-LEAP: $\mathrm{N}^{\circ}$ 227822, SHARE M4: $\mathrm{N}^{\circ}$ 261982). Additional funding from the German Ministry of Education and Research, the U.S. National Institute on Aging (U01_AG0974013S2, P01_AG005842, P01_AG08291, P30_AG12815, R21_AG025169, Y1-AG-4553-01, IAG_BSR06-11, OGHA_04-064) and from various national funding sources is gratefully acknowledged (see www.share-project.org). 


\subsection{Operationalization}

As dependent variables we use three health indicators. The number of chronic conditions is used to operationalize physical health. A measure for self-rated health is used ranging from 1 (excellent) to 5 (poor). To operationalize mental health we use the EURO Depression Scale provided in SHARE (Prince et al. 1999). The scale is an additive index reporting the number of depressive symptoms, ranging from 1 to 12 with higher values reflecting greater levels of depressive feelings. We operationalize the fertility history by means of two indicators: the number of children in three groups: no children (used as reference category), one to two children, three or more children; and the age at the birth of the first child. The life-course factors span the period from the year 1935, when the oldest sample members were 15 years old, to 2008, when the youngest became 59 years. To take into account health selectivity with respect to fertility behaviour, we control for respondents' childhood health and their parents' mortality. The information on childhood health status refers to the period from birth until the respondent become 16 years old and comprises three variables: self-rated health; whether parents smoked; and whether the respondent was confined to bed or home for one month or longer due to illness or disability. The variable on parents' survival is differentiated in three categories for each parent: mother/father died before age 60 (used as reference category); died between ages 60-74; and died at age older than 75 or is not deceased at the time of the interview. It provides a proxy information on an individual's genetic health disposition.

To analyse cohort differences, we assigned the respondents to two cohorts: those born between 1920 and 1944 are the older cohort; born between 1945 and 1959 are the younger cohort. To differentiate welfare state types, we use a categorisation in four groups following Castles and Obinger (2008): the largest group of Continental countries comprises Austria, Belgium, France, West Germany, The Netherlands, and Switzerland ${ }^{3}$; Scandinavian/Social-democratic are Denmark and Sweden; Southern European countries are Italy and Spain; the Central and Eastern European group comprises countries with a socialist legacy, those are the Czech Republic, East Germany, and Poland. As exogenous control variables we include age and marital status. Furthermore, we control for several socioeconomic status indicators including years of education, whether a respondent was active on the labour market, homeownership, and the logarithmized household income. Table A.1 in the Appendix gives an overview of all variables included in the statistical estimations.

$3 \quad$ Switzerland and the Netherlands are ambiguous cases which have been assigned to different regimes in welfare state typologies. In this more historic perspective and in the absence of other liberal countries, we consider their assignment to the Continental cluster as most adequate for our data. 


\subsection{Methods}

Multilevel regressions were estimated using Country Fixed Effects models. These regression models are appropriate for data-sets with a small number of macro-level units $(\mathrm{N}<20)$, since they control for the residual variance on the country level (Allison 2009; Möhring 2012; Maas and Hox 2005). The regression equation for these kind of models is (linear model):

$$
y_{i j}=\underbrace{y_{0}+\beta_{1} x_{1 i j}+\ldots+\beta_{k} x_{k i j}+\alpha_{1} u_{j 1}+\ldots+\alpha_{N-1} u_{j N-1}}_{\text {fixed part }}+\underbrace{e_{i j}}_{\text {random part }}
$$

with

$y_{i j}$ : Individual-level outcome of observation $i$ in country $j$

$y_{0}$ : Intercept over all countries

$\beta_{k} x_{k i j}$ : Estimator of individual-level variable number $k$ of observation $i$ in country $j$ $\alpha_{1} u_{j 1}+\ldots+\alpha_{n-1} u_{j n-1}$ : fixed effects for the N-1 countries

$e_{i j}$ : Residual variance for observation $i$ within country $j$

As the metric of the outcome variable varies, we use different regression model specifications: negative binominal models to analyse the number of chronic conditions; ordered logit models for the self-rated health with five values; and OLS linear regression models for the continuous EURO Depression scale. All regression models are estimated separately for men and women and include the variables on the fertility history (number of children; age at first birth), on childhood and adolescence health until age 16 (self-rated health; periods of confined to bed/home for more than one month); parents' health behaviour when the respondent was young (parents smoked); parents' mortality (mother's survival status; father's survival status), as well as the control variables, socioeconomic status, and the country dummies as described above.

\section{Results}

Table 1 includes the results of the multivariate models for our three dependent variables separated by gender. In all models, we control for childhood health conditions, parents' mortality, and several indicators associated to the respondents' current socio-economic status. Our main variables of interest are the number of children and age at the birth of the first child.

First of all, differences between parents and childless individuals as well as according to the number of children are weak. Only depressive feelings for women and chronic conditions for men are significantly related with childlessness and parity. Women with one or two children have on average a 0.65 scale points reduction in the number of depressive symptoms compared to childless women. Additional analyses 


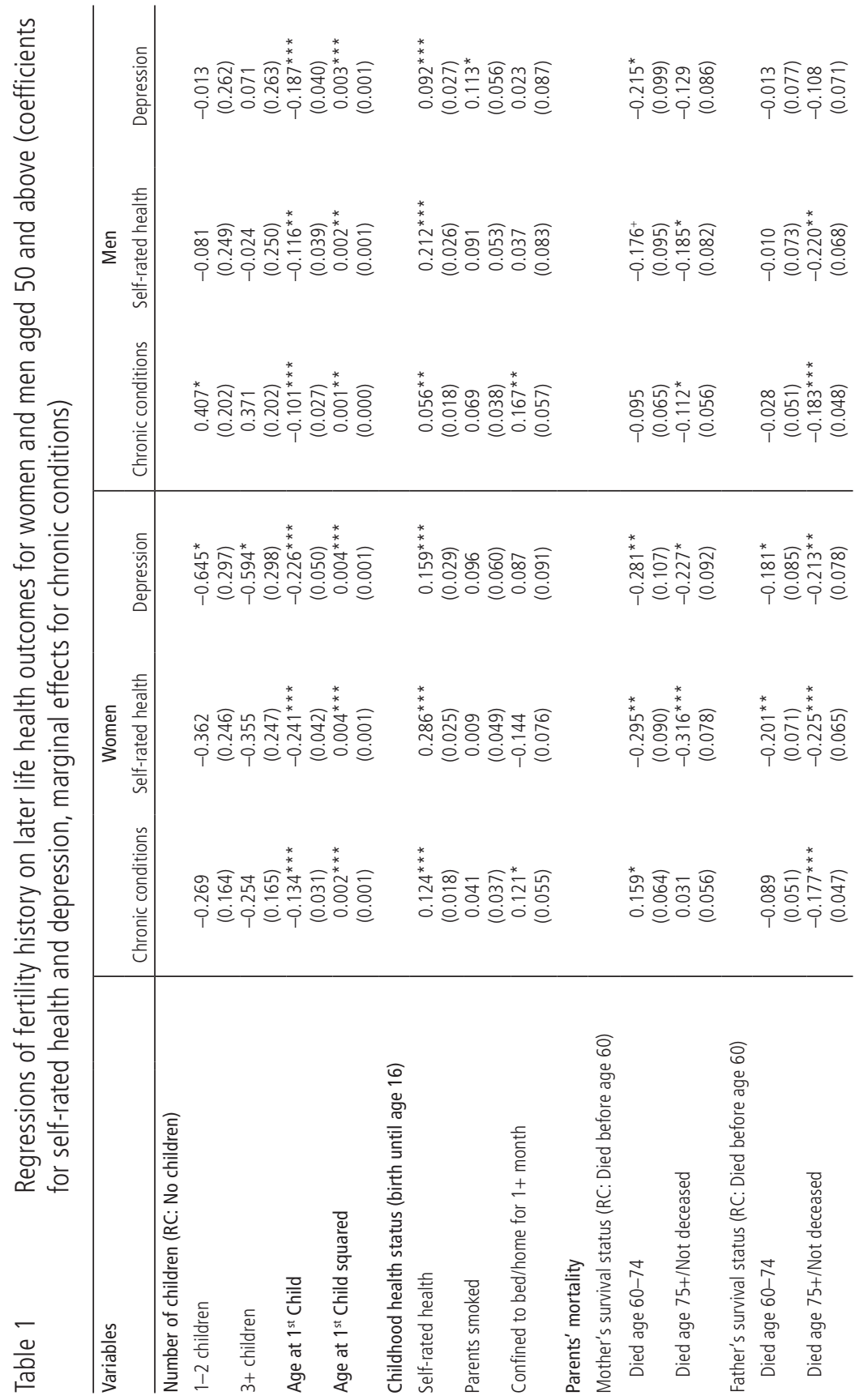




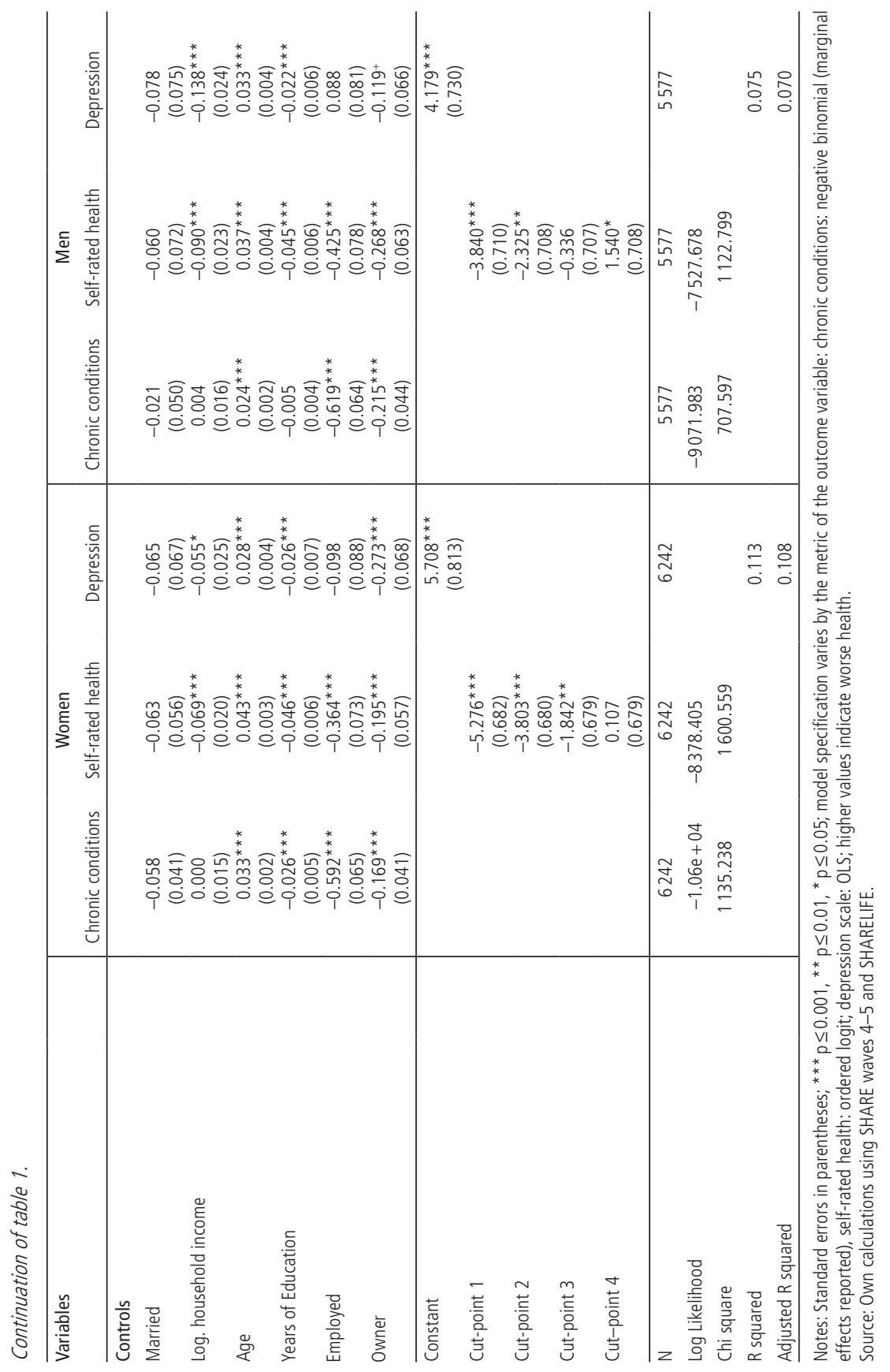


have shown that this result only applies to older women (age 65 and above), whereas for the younger of age 50 to 64 no significant differences in depressive symptoms between childless women and mothers exist (see Table A.2 in the Appendix). The reverse relationship exists for men's physical health: men with one or two children have on average a 0.41 scale points higher number of chronic conditions, while there is no significant difference between men with three or more children and childless men. To sum up, we do not find evidence to support our first hypothesis: parents are not in better health than childless individuals, the only exception being depressive feelings among women. With respect to physical health of men we even find those without children to be in a better condition than parents. Therefore, Hypothesis 2 assuming worse health for individuals with a high number of children is only supported with respect to men's chronic conditions.

Timing of the first birth, however, is significantly associated with later life health for both genders. As the linear and the quadratic term are significant, the relationship of age at first birth and later life health appears to be u-shaped for all health outcomes. Accordingly, for mothers and fathers, health improves with increasing age at childbirth until a certain age and then declines. While the effect strength for chronic conditions is similar for men and women, gender differences exist for self-rated health and depressive feelings. For both outcomes, the interrelation of age at first child and later life health is much stronger for women compared to men. Also for men, the curvilinear relationship is not as pronounced as for women. The relationship of men's physical health in later life and age at first birth appears to be almost linear with negative health consequences only for very young fathers (Figure 1). To sum up, early as well as late parenthood have detrimental health consequences for both genders. Therefore, our Hypothesis 3 is supported, while the u-shaped relationship assumed in Hypothesis 4 only for women in fact applies to both genders. Only for chronic conditions we find an almost linear relationship for men indicating that health continuously improves with delaying childbirth.

The relationship of parity and later life health differs between birth cohorts for women (Figure 2). While for those born between 1920 and 1944 significant health differences exist according to number of children, the relationship is insignificant in the younger cohorts born between 1945 and 1959. For the older cohorts, the later life health status is the better, the more children a women has. For men, the number of children is neither in the older nor in the younger cohort significantly related to any later life health outcome. Figure 1 shows the marginal effects of age at first child for both genders and all health outcomes separated for birth cohorts of 1920 to 1944 and 1945 to 1959 . For all outcomes, significant differences between the two cohorts exist indicating better health outcomes for the younger cohort. The cohort differences are smallest for depressive symptoms and largest for chronic conditions for both genders. Apart from depressive symptoms for men, the negative effect of lower age at first birth is smaller in the younger cohort. Accordingly, 
Figure $1 \quad$ Marginal effects of the health outcomes according to of age at first child for different cohorts
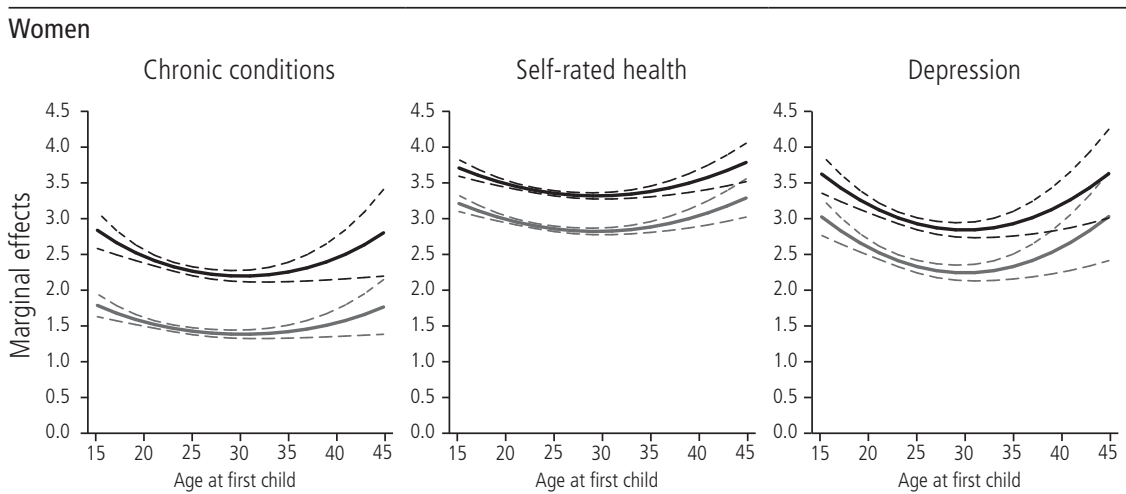

Men

Chronic conditions

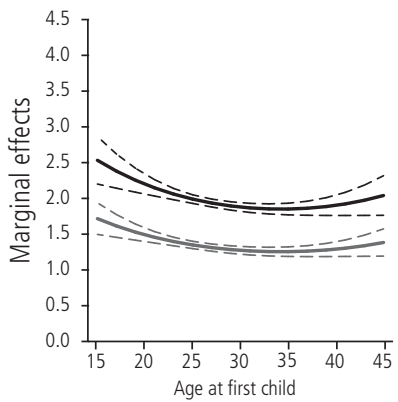

Self-rated health

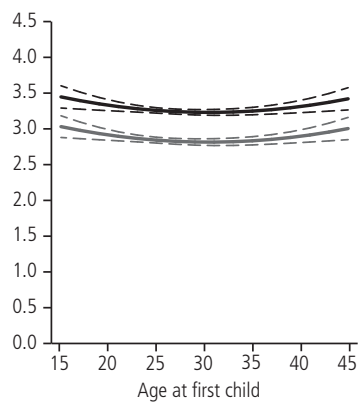

Depression

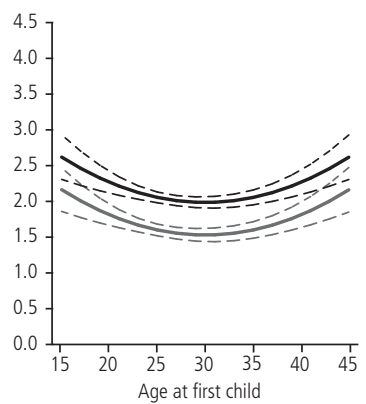

— born 1920-1944 — born 1945-1959

Notes: Regression models include all variables as presented in Table 1; for simplified presentation results for self-rated health based on linear regression models.

Source: Own calculations using SHARE waves $4-5$ and SHARELIFE.

we find support for Hypothesis 6 stating that the detrimental health effects of high parity and low age at first birth are smaller in the younger cohort. Significant differences between individuals' health according to number of children can only be found among women born 1920 to 1944 , and this effect mainly stems from the worse later life health of childless women in this cohort.

An analysis separated for welfare state types gives more indication on the prevalence of the u-shaped relationship between age at first child and later life health. Figure 3 depicts the marginal effects of age at first child for both genders and all health outcomes separated for the four country groups Continental, Scandinavian, 
Figure 2 Predicted values of the health outcomes according to number of children for different cohorts

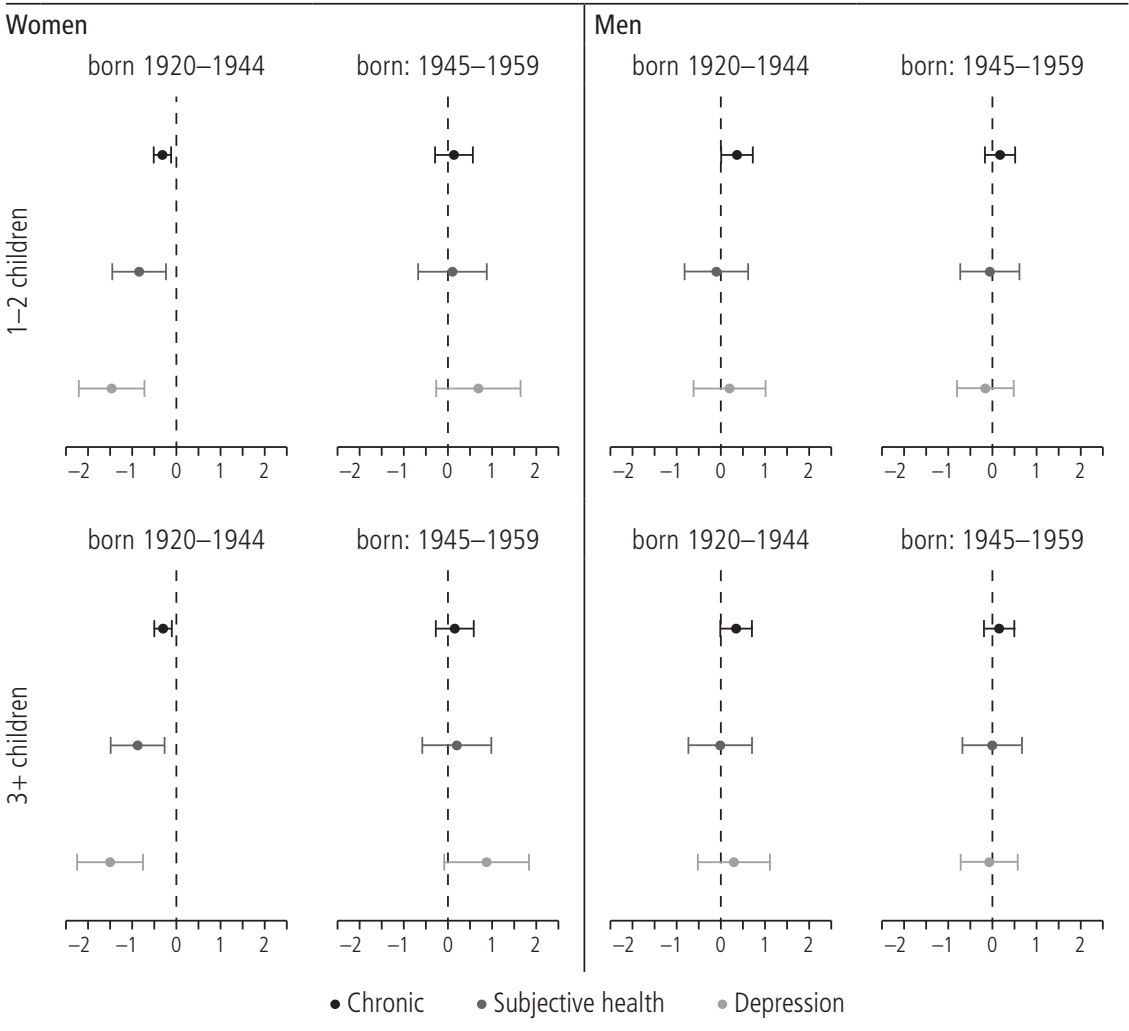

Notes: Regression models include all variables as presented in Table 1.

Source: Own calculations using SHARE waves $4-5$ and SHARELIFE.

Eastern and Southern European states. The differences between these regions are largest for self-rated health, and small for chronic conditions, especially women's. In Eastern and Southern European countries later life health appears to be generally on a lower level, however, the relationship of fertility timing and health is less intense in these countries. The pronounced $u$-shaped relationship of age at first child and health outcomes, which emerged in the combined regressions, applies only to women in Continental and Scandinavian countries, while we find rather linear relationships in Eastern and Southern countries. For men, only in continental welfare states a clear u-shaped pattern emerges for all health outcomes. Differences in later life health according to the number of children are insignificant for both genders in all welfare state types with the only exception being depression among women in 
Figure 3

Marginal effects of the health outcomes according to of age at first child for different regions
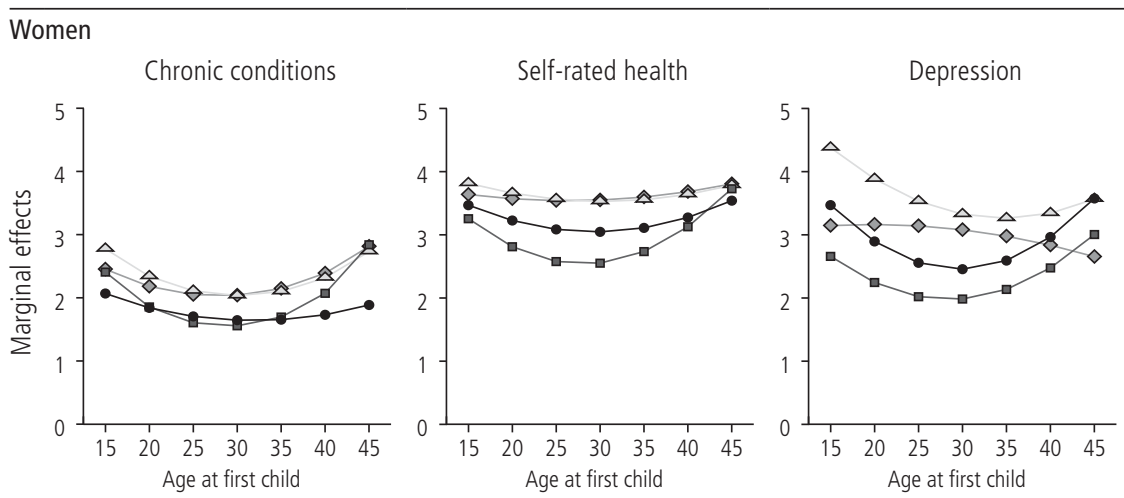

Men

Chronic conditions

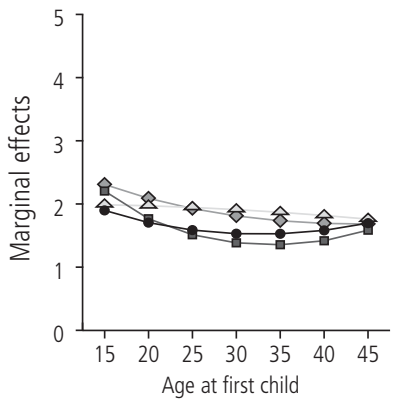

$\rightarrow$ Continental
Self-rated health

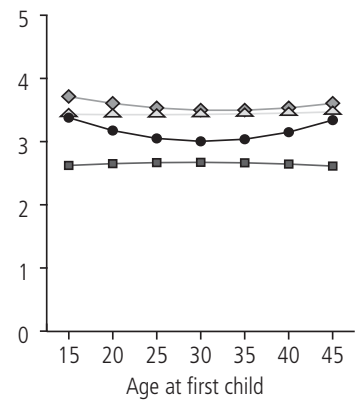

$\rightarrow$ Scandinavian

$\diamond$ Eastern
Depression

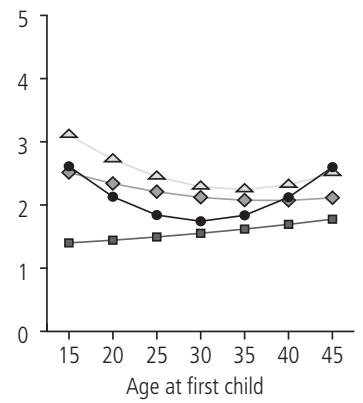

$\Delta$ Southern

Notes: Regression models include all variables as presented in Table 1; for simplified presentation results for self-rated health based on linear regression models.

Source: Own calculations using SHARE waves 4-5 and SHARELIFE.

Continental countries. Here, childless women have an increased likelihood to suffer from depressive symptoms (Figures A.1 and A.2 in the Appendix). To sum up, we do not find clear evidence to support our last hypothesis that negative effects of higher parity and lower age at first birth are smaller in welfare states providing more generous family policy and services. With respect to age at first child, a clear age structured pattern can only be found in Continental and Scandinavian countries.

The final models we report in Table 1 all include indicators for childhood health and parents' mortality to control to some degree for selection effects into fertility behavior. For both genders and all later life health outcomes, the general health status during childhood is a strong predictor: those who suffered from bad health 
at young ages have an increased likelihood for worse physical and mental health in later life than their counterparts with no health problems during childhood. We also find a positive significant relationship between severe illnesses in childhood (being confined to bed or home for one month or more) and chronic conditions in later life. Furthermore, parents' mortality is mostly significantly related to their children's health in later life: if parents lived longer or are still alive, children's health status is usually better. Only for men's mental health parents' mortality is irrelevant and the relationship between women's chronic conditions and their mothers' mortality is reversed. The results indicate that genetic disposition (operationalized by own parents' longevity) and childhood conditions have a significant impact on an individuals' later life health. However, none of the fertility history indicators (parity and timing of first birth) changes their significance or effect direction after including the variables for childhood and parents' health. This gives some indication that selection effects do not play a large role or different types of selection effects cancel each other out for the outcomes we are interested in. An exception are the women of the older birth cohort: the fact that here childless women suffer from worse mental and physical health than their counterparts with children hints to involuntary childlessness due to predispositions. However, generally it would be necessary to have more detailed health history information covering the whole life span to rule out all selectivity effects.

\section{Conclusion}

Based on life course data from the Survey of Health, Ageing and Retirement (SHARE), we investigated the role of fertility history for later life health across two birth cohorts and 13 European countries. The central findings are that parenthood and the number of children have little impact on health in later life, while the timing of the first birth is important across health outcomes for both men and women.

First, our results indicate that mothers are in better (mental) health in later life than childless women, while there is no relationship for men. Mothers with three or more children do not differ from those with one or two children. This confirms earlier research which found either no effects or benefits of parenthood for later life health (e. g., Eggebeen and Knoester 2001; Teachman 2010, see section 3.1). Previous research also indicated that parenthood effects vary across countries (e.g. Grundy 2009). Indeed, our study shows that the health benefits of parenthood are limited to the older cohort (born between 1920 and 1945) and mothers in Continental Europe.

Second, fertility timing is important for all three health outcomes. Delaying childbirth until 30 years at age of first birth is beneficial for both men and women, but more so for mothers. However, late childbearing (>35) is also more detrimental 
to women's than to men's health. The lesson we learn from this - confirming previous research (e.g. Mirowsky 2002; Mirowsky 2005, see section 3.4), is that delaying childbirth until the 30 s is beneficial to parents' later life health. Considering that in our sample, $55 \%$ of the women and $25 \%$ of the men had their first child before 25 , we might expect that the demographic trends towards later childbirth since the 1960s (2014 the mean age of women at first birth was 28.9 in the European Union), has been a positive development with respect to population health.

Finally, our study adds to the literature insights that can be drawn from comparing the timing effect across different health outcomes, cohorts, and welfare regimes. On the one hand, this comparison suggests that first births between 25 and 30 for women and (less consistently) between 25 and 35 for men are associated with the best later life health outcomes in almost all of our analysis groups. This universal pattern indicates that biological mechanisms partially account for the relationship between timing and later life health, particularly for mothers. On the other hand, there is substantial variation in the degree to which timing matters for health across contexts. This indicates that social mechanisms play a powerful role in this relationship. In terms of historical context, we find that timing of first birth has become less important in younger cohorts. This suggests - in line with our theoretical expectations - that in times of greater prosperity, social security and availability of safe maternity care an early age at first birth will be less problematic for later life health. Our study did not directly test the relative importance of biological, social, and selection mechanisms. However, the wide variation that timing effects have across contexts and the decreased importance over historical time suggests that the inevitable health costs of both teenage and late childbearing should not be exaggerated (Furstenberg 2007), since the social context strongly affects their implications for health. Identifying the underlying institutional and normative variables of these context effects will provide insights into the causes of timing effects and potentially opportunities for social intervention. However, one also needs to consider that paternal age has also other implications, most importantly probably the health and developmental outcomes of children. Children from teenage parents are more likely to have poorer behavioral and psychological outcomes (Shaw et al. 2006). A higher maternal age has mixed effects for children. On the one hand it increases the risks for chromosomal abnormalities and adverse neonatal outcomes for a small group of children (Kozuki et al. 2013; Restrepo-Méndez et al. 2015), but is generally associated with better cognitive ability of children in more recent cohorts (Goisis et al. 2017).

Our aim was to explore the role of one contextual variable, welfare state arrangements, in our country-comparative analysis of timing effects. However, the patterns that we found across countries were more complex and did not confirm our expectations that the generosity of parental leave and childcare services are the primary mechanism behind cross-national variation in timing effects. For 
women, timing matters to a much larger degree in Continental and Scandinavian countries than in Eastern or Southern Europe. For men, timing matters mostly in Continental Europe, while for the other country groups the results vary across outcomes, but mostly show less impact of timing. The implication of the result that there are stronger differences between Continental/Scandinavian compared to Eastern/Southern European countries might suggest two venues for further research of context effects. First, fertility trends in the number and timing of children developed quite differently in these two country groups than in Continental Europe and Scandinavia which show similar trends as the Anglo-Saxon countries which are most researched for parenthood health effects (Tomka 2013; Freijka 2016). Second, Eastern and Southern European countries had political dictatorships after WWII, while Continental Europe and Scandinavia were democratic. To gain deeper insights into the relative importance of these factors and welfare state development, it seems particularly important for further research to differentiate between country groups and cohorts and if possible include younger cohorts, e. g. who experienced democratization in Southern Europe.

The results of our study are restricted by several limitations. First, as we rely on cross-sectional information on the health outcomes, we are unable to track health changes throughout later life. So, our study cannot inform about the change and duration of specific health conditions in later life. Second, the life course information provided in SHARELIFE may suffer from retrospective memory bias. The respondents who were between the age of 50 and 91 were asked to recall information from the period that they were 15 to 49 , which may not be remembered accurately. However, the approach using calendar interviews in SHARELIFE is likely to have limited this bias (Schröder, 2011). Finally, our results may be biased due to selective mortality.

\section{References}

Aassve, Arnstein, Stefano Mazzuco, and Letizia Mencarini. 2005. Childbearing and Well-Being: A Comparative Analysis of European Welfare Regimes. Journal of European Social Policy 15(4): 283-299.

Aitken, Zoe, Cameryn C. Garrett, Belinda Hewitt, Louise Keogh, Jane S. Hocking, and Anne M. Kavanagh. 2015. The Maternal Health Outcomes of Paid Maternity Leave: A Systematic Review. Social Science \& Medicine 130: 32-41.

Allison, Paul D. 2009. Fixed Effects Regression Models. Thousand Oaks: SAGE Publications.

Arnett, Jeffrey J. 1998. Risk Behavior and Family Role Transitions During the Twenties. Journal of Youth and Adolescence 27(3): 301-320.

Bambra, Clare. 2006. Health Status and the Worlds of Welfare. Social Policy and Society 5(1): 53-62.

Barban, Nicola. 2013. Family Trajectories and Health: A Life Course Perspective. European Journal of Population/Revue européenne de Démographie 29(4): 357-385. 
Beckfield, Jason, Clare Bambra, Terje A. Eikemo, Tim Huijts, Courtney McNamara, and Claus Wendt. 2015. An Institutional Theory of Welfare State Effects on the Distribution of Population Health. Social Theory \& Health 13(3-4): 227-244.

Ben-David, Alon, Saralee Glassner, Eyal Schiff, Aliza S. Zahav, Valentina Boyko, and Liat Lerner-Geva. 2016. Pregnancy and Birth Outcomes Among Primaparae at Very Advanced Maternal Age: At What Price? Maternal and Child Health Journal 20: 833-842.

Billari, Francesco C., Hans-Peter Kohler, Gunnar Andersson, and Hans Lundström. 2007. Approaching the Limit: Long-Term Trends in Late and Very Late Fertility. Population and Development Review 33(1): 149-170.

Börsch-Supan, Axel, Martina Brandt, Christian Hunkler, Thorsten Kneip, Julie Korbmacher, Frederic Malter, Barbara Schaan, Stephanie Stuck, and Sabrina Zuber. 2013. Data Resource Profile: The Survey of Health, Ageing and Retirement in Europe (SHARE). International Journal of Epidemiology 42(4): 992-1001.

Breart, Gérard. 1997. Delayed Childbearing. European Journal of Obstetrics \& Gynecology and Reproductive Biology 75(1): 71-73.

Brockmann, Hilke and Thomas Klein. 2004. Love and Death in Germany: The Marital Biography and Its Effect on Mortality. Journal of Marriage and Family 66(3): 567-581.

Burton-Jeangros, Claudine, Stéphane Cullati, Amanda Sacker, and David Blane (eds.). 2015. A Life Course Perspective on Health Trajectories and Transitions. Cham: Springer.

Carlson, Daniel L. 2011. Explaining the Curvilinear Relationship Between Age at First Birth and Depression Among Women. Social Science \& Medicine 72(4): 494-503.

Castles, Francis G. and Herbert Obinger. 2008. Worlds, Families, Regimes: Country Clusters in European and OECD Area Public Policy. West European Politics 31(1/2): 321-344.

Curtis, Lori and Shelley Phipps. 2004. Social Transfers and the Health Status of Mothers in Norway and Canada. Social Science \& Medicine 58(12): 2499-2507.

DiPrete, Thomas A. and Gregory M. Eirich. 2006. Cumulative Advantage as a Mechanism for Inequality: A Review of Theoretical and Empirical Developments. Annual Review of Sociology 32(1): 271-297.

Eggebeen, David J. and Chris Knoester. 2001. Does Fatherhood Matter for Men? Journal of Marriage and Family 63(2): 381-393.

Freijka, Tomas. 2016. The Demographic Transition Revisited: A Cohort Perspective. Max Planck Institute for Demographic Research Working Paper, Rostock.

Furstenberg, Frank F. 2007. Destinies of the Disadvantaged: The Politics of Teen Childbearing. New York: Russell Sage Foundation.

Furstenberg Jr., Frank F., Jeanne Brooks-Gunn, and S. Philip Morgan. 1987. Adolescent Mothers in Later Life. New York, NY, US: Cambridge University Press.

Gibney, Sarah, Liam Delaney, Mary Codd, and Tony Fahey. 2015. Lifetime Childlessness, Depressive Mood and Quality of Life Among Older Europeans. Social Indicators Research 130(1): 1-19.

Goisis, Alice, Daniel C. Schneider, and Mikko Myrskylä. 2017. The Reversing Association Between Advanced Maternal Age and Child Cognitive Ability: Evidence From Three UK Birth Cohorts. International Journal of Epidemiology 46(3): 850-859.

Goode, William J. 1960. A Theory of Role Strain. American Sociological Review 25(4): 483-496.

Grundy, Emily. 2009. Women's Fertility and Mortality in Late Mid Life: A Comparison of Three Contemporary Populations. American Journal of Human Biology: The Official Journal of the Human Biology Council 21: 541-547.

Grundy, Emily and Cecilia Tomassini. 2005. Fertility History and Health in Later Life: A Record Linkage Study in England and Wales. Social Science \& Medicine 61(1): 217-228.

Hank, Karsten. 2010. Childbearing History, Later-Life Health, and Mortality in Germany. Population Studies 64(3): 275-291. 
Hansen, Thomas. 2012. Parenthood and Happiness: A Review of Folk Theories Versus Empirical Evidence. Social Indicators Research 108(1): 29-64.

Helbig, Sylvia, Thomas Lampert, Michael Klose, and Frank Jacobi. 2006. Is Parenthood Associated With Mental Health? Findings From an Epidemiological Community Survey. Social Psychiatry and Psychiatric Epidemiology 41(11): 889-896.

Henretta, John C. 2007. Early Childbearing, Marital Status, and Women's Health and Mortality After Age 50. Journal of Health and Social Behavior 48(3): 254-266.

Huijts, Tim, Gerbert Kraaykamp, and Subbaya V. Subramanian. 2013. Childlessness and Psychological Well-Being in Context: A Multilevel Study on 24 European Countries. European Sociological Review 29(1): 32-47.

Hurt, Lisa S., Carine Ronsmans, and Sara L. Thomas. 2006. The Effect of Number of Births on Women's Mortality: Systematic Review of the Evidence for Women Who Have Completed Their Childbearing. Population Studies 60(1): 55-71.

Kennedy, Patricia, Naonori Kodate, and Nadine Reibling. 2015. Welfare Regimes, Healthcare Regimes and Maternity Services and Policy: A Comparative Perspective. Pp. 4-19 in Maternity Services and Policy in an International Context: Risk, Citizenship, and Welfare Regimes, edited by Patricia Kennedy and Naonori Kodate. Abingdon: Routledge.

Kington, Raynard, Lee Lillard, and Jeannette Rogowski. 1997. Reproductive History, Socioeconomic Status, and Self-Reported Health Status of Women Aged 50 Years or Older. American Journal of Public Health 87(1): 33-37.

Kohler, Hans-Peter, Jere R. Behrman, and Axel Skytthe. 2005. Partner Plus Children = Happiness? The Effects of Partnerships and Fertility on Well-Being. Population and Development Review 31(3): 407-445.

Kozuki, Naoko, Anne C. C. Lee, Mariangela F. Silveira, Ayesha Sania, Joshua P. Vogel, Linda Adair, Fernando Barros, Laura E. Caulfield, Parul Christian, Wafaie Fawzi, Jean Humphrey, Lieven Huybregts, Aroonsri Mongkolchati, Robert Ntozini, David Osrin, Dominique Roberfroid, James Tielsch, Anjana Vaidya, Robert E. Black, Joanne Katz, and Child Health Epidemiology Reference Group (CHERG) Small-for-Gestational Age Preterm Birth Working Group. 2013. The Associations of Parity and Maternal Age With Small-for-Gestational Age, Preterm, and Neonatal and Infant Mortality: A Meta-Analysis. BMC Public Health 13(3): 5.

Kroll, Lars Eric, Stephan Mueters, Petra Rattay, and Thomas Lampert. 2016. Employment, Family and Health in Men of Working Age in Germany Results of the GEDA Studies 2009-2012. Bundesgesundheitsblatt-Gesundheitsforschung-Gesundheitsschutz 59(8): 932-941.

Lacey, Rebecca, Amanda Sacker, Steven Bell, Meena Kumari, Diana Worts, Peggy McDonough, Diana Kuh, and Anne McMunn. 2017. Work-Family Life Courses and BMI Trajectories in Three British Birth Cohorts. International Journal of Obesity 41: 332-339.

Lisonkova, Sarka, Jayson Potts, Giulia M. Muraca, Neda Razaz, Yessar Sabr, Wee-Shian Chan, and Michael S. Kramer. 2017. Maternal Age and Severe Maternal Morbidity: A Population-Based Retrospective Cohort Study. PLoS Medicine 14(5): e1002307.

Loudon, Irvine. 2000. Maternal Mortality in the Past and Its Relevance to Developing Countries Today. The American Journal of Clinical Nutrition 72(1): 241-246.

Maas, Cora J. M, and Joop J. Hox. 2005. Sufficient Sample Sizes for Multilevel Modeling. Methodology 1(3): 86-92.

Marks, Stephen R. 1977. Multiple Roles and Role Strain: Some Notes on Human Energy, Time and Commitment. American Sociological Review 42(6): 921-936.

Mayer, Karl Ulrich. 2009. New Directions in Life Course Research. Annual Review of Sociology 35(1): 413-433.

Merrill, Ray M., Stephanie Fugal, Lelinneth B. Novilla, and Matthew C. Raphael. 2005. Cancer Risk Associated With Early and Late Maternal Age at First Birth. Gynecologic Oncology 96(3): 583-593. 
Mirowsky, John. 2005. Age at First Birth, Health, and Mortality. Journal of Health and Social Behavior 46(1): 32-50.

Mirowsky, John and Catherine E Ross. 2002. Depression, Parenthood, and Age at First Birth. Social Science \& Medicine 54(8): 1281-1298.

Mirowsky, John. 2002. Parenthood and Health: The Pivotal and Optimal Age at First Birth. Social Forces 81(1): 315-349.

Möhring, Katja. 2012. The Fixed Effects Approach as Alternative to Multilevel Models for Cross-National Analyses. Paper presented at the $10^{\text {th }}$ ESPAnet Conference, Edinburgh, Scotland, September 6-8, 2012.

Muñoz, Nubia, Silvia Franceschi, Cristina Bosetti, Victor Moreno, Rolando Herrero, Jennifer S. Smith, Keerti V. Shah, Chris J.L. M. Meijer, and F. Xavier Bosch. 2002. Role of Parity and Human Papillomavirus in Cervical Cancer: The IARC Multicentric Case-Control Study. The Lancet 359(9312): 1093-1101.

Nauck, Bernhard, Chin-Chun Yi, Johannes Huinink, and Michael Feldhaus. 2009. Family Research From the Life Course Perspective. International Sociology 24(3): 299-324.

Nomaguchi, Kei M. and Suzanne M. Bianchi. 2004. Exercise Time: Gender Differences in the Effects of Marriage, Parenthood, and Employment. Journal of Marriage and Family 66(2): 413-430.

Nomaguchi, Kei M. and Melissa A. Milkie. 2003. Costs and Rewards of Children: The Effects of Becoming a Parent on Adults' Lives. Journal of Marriage and Family 65(2): 356-374.

O'Flaherty, Martin, Janeen Baxter, Michele Haynes, and Gavin Turrell. 2015. Age at First Birth and Long-Term Health in Life Course Perspective: Contextualizing the Health Effects of Fertility Timing. The Australian Research Council Life Course Centre Working Paper Series 28.

Orloff, Ann Shola. 1993. Gender and the Social Rights of Citizenship: The Comparative Analysis of Gender Relations and Welfare States. American Sociological Review 58(3): 303-328.

Ozalp, Sinan, Huseyin Mete Tanir, Turgay Sener, Sibel Yazan, and Ali E. Keskin. 2003. Health Risks for Early ( $\leq 19)$ and Late ( $\geq 35)$ Childbearing. Archives of Gynecology and Obstetrics 268(3): 172-174.

Prince, Martin J., Reischies F., A. T. F. Beekman, R. Fuhrur, C. Jonker, S. L. Kivela, B. A. Lawtor, A. Lobo, H. Magnusson, M. Fichter, H. van Oyen, M. Roelands, I. Skoog, C. Turrina, J. R. M. Copeland. 1999. Development of the EURO-D Scale - a European, Union Initiative to Compare Symptoms of Depression in 14 European Centres. The British Journal of Psychiatry 174(4): 330-338.

Read, Sanna and Emily Grundy. 2011. Fertility History and Quality of Life in Older Women and Men. Ageing \& Society 31(1): 125-145.

Read, Sanna, Emily Grundy, and Douglas A. Wolf. 2011. Fertility History, Health, and Health Changes in Later Life: A Panel Study of British Women and Men Born 1923-1949. Population Studies 65(2): 201-215.

Restrepo-Méndez, Maria C., Debbie A. Lawlor, Bernardo L. Horta, Alicia Matijasevich, Iná S. Santos, Ana M. B. Menezes, Fernando, C. Barros, and Cesar G. Victora. 2015. The Association of Maternal Age With Birthweight and Gestational Age: A Cross-Cohort Comparison. Paediatric and Perinatal Epidemiology 29: 31-40.

Russo, Jose, Raquel Moral, Gabriela A. Balogh, Daniel Mailo, and Irma H. Russo. 2005. The Protective Role of Pregnancy in Breast Cancer. Breast Cancer Research: BCR 7(3): 131-142.

Scalone, Francesco. 2014. Effects of Nutritional Stress and Socio-Economic Status on Maternal Mortality in Six German Villages, 1766-1863. Population Studies 68(2): 217-236.

Schröder, M. (ed.). 2011. Retrospective Data Collection in the Survey of Health, Ageing and Retirement in Europe. SHARELIFE Methodology. Mannheim: Mannheim Research Institute for the Economics of Aging (MEA). 
Shaw, Mary, Debbie A. Lawlor, and Jake M. Najman. 2006. Teenage Children of Teenage Mothers: Psychological, Behavioral, and Health Outcomes From an Australian Prospective Longitudinal Study. Social Science \& Medicine 62(10): 2526-2539.

Sieber, Sam D. 1974. Toward a Theory of Role Accumulation. American Sociological Review 39(4): 567-578.

Spence, Naomi J. 2008. The Long-Term Consequences of Childbearing: Physical and Psychological Well-Being of Mothers in Later Life. Research on Aging 30(6): 722-751.

Tanaka, Kimiko and Nan E. Johnson. 2014. Childlessness and Mental Well-Being in a Global Context. Journal of Family Issues 37(8): 1027-1045.

Taylor, Julie Lounds. 2009. Midlife Impacts of Adolescent Parenthood. Journal of Family Issues 30(4): 484-510.

Teachman, Jay. 2010. Family Life Course Statuses and Transitions: Relationships With Health Limitations. Sociological Perspectives 53(2): 201-219.

Tomka, Béla. 2013. A Social History of Twentieth-Century Europe. Abingdon: Routledge.

Umberson, Debra, Tetyana Pudrovska, and Corinne Reczek. 2010. Parenthood, Childlessness, and Well-Being: A Life Course Perspective. Journal of Marriage and Family 72(3): 612-629.

Westendorp, Rudi. G. and Thomas B. Kirkwood. 1998. Human Longevity at the Cost of Reproductive Success. Nature 396(6713): 743-746.

Yi, Zeng and James Vaupel. 2004. Association of Late Childbearing With Healthy Longevity Among the Oldest-Old in China. Population Studies 58(1): 37-53. 


\section{$9 \quad$ Appendix}

Table A.1 Summary statistics for the variables used for the statistical estimations

\begin{tabular}{|c|c|c|c|c|c|c|c|c|}
\hline \multirow[t]{2}{*}{ Variables } & \multicolumn{4}{|c|}{ Women } & \multicolumn{4}{|c|}{ Men } \\
\hline & Mean & $\begin{array}{l}\text { Standard } \\
\text { Deviation }\end{array}$ & Minimum & Maximum & Mean & $\begin{array}{l}\text { Standard } \\
\text { Deviation }\end{array}$ & Minimum & Maximum \\
\hline Number of chronic diseases & 1.90 & 1.60 & 0 & 13 & 1.68 & 1.47 & 0 & 10 \\
\hline Self-perceived health & 3.15 & 1.07 & 1 & 5 & 3.08 & 1.05 & 1 & 5 \\
\hline EURO depression scale & 2.71 & 2.34 & 0 & 12 & 1.87 & 1.99 & 0 & 12 \\
\hline Age at $1^{\text {st }}$ Child & 24.78 & 4.41 & 15 & 46 & 27.73 & 4.74 & 17 & 55 \\
\hline Age at $1^{\text {st }}$ Child squared & 633.60 & 238.26 & 225 & 2116 & 791.55 & 289.55 & 289 & 3025 \\
\hline \multicolumn{9}{|l|}{ Number of children } \\
\hline No children & 0.01 & 0.09 & 0 & 1 & 0.01 & 0.10 & 0 & 1 \\
\hline $1-2$ children & 0.62 & 0.48 & 0 & 1 & 0.61 & 0.49 & 0 & 1 \\
\hline $3+$ children & 0.37 & 0.48 & 0 & 1 & 0.38 & 0.49 & 0 & 1 \\
\hline Childhood health status & 2.09 & 1.01 & 1 & 5 & 2.03 & 1.00 & 1 & 5 \\
\hline Parents smoked & 0.62 & 0.48 & 0 & 1 & 0.66 & 0.48 & 0 & 1 \\
\hline $\begin{array}{l}\text { confined to bed/ } \\
\text { home } 1+\text { month }\end{array}$ & 0.11 & 0.32 & 0 & 1 & 0.11 & 0.31 & 0 & 1 \\
\hline \multicolumn{9}{|l|}{ Mother's survival status } \\
\hline Died age $60-74$ & 0.11 & 0.31 & 0 & 1 & 0.11 & 0.31 & 0 & 1 \\
\hline Died age $60-74$ & 0.18 & 0.39 & 0 & 1 & 0.19 & 0.39 & 0 & 1 \\
\hline $\begin{array}{l}\text { Died age } 75+/ \\
\text { Not deceased }\end{array}$ & 0.71 & 0.46 & 0 & 1 & 0.71 & 0.45 & 0 & 1 \\
\hline \multicolumn{9}{|l|}{ Father's survival status } \\
\hline Died age 60-74 & 0.18 & 0.38 & 0 & 1 & 0.18 & 0.39 & 0 & 1 \\
\hline Died age $60-74$ & 0.29 & 0.46 & 0 & 1 & 0.30 & 0.46 & 0 & 1 \\
\hline $\begin{array}{l}\text { Died age } 75+l \\
\text { Not deceased }\end{array}$ & 0.53 & 0.50 & 0 & 1 & 0.51 & 0.50 & 0 & 1 \\
\hline Age & 67.90 & 9.04 & 52 & 91 & 68.94 & 8.58 & 52 & 91 \\
\hline \multicolumn{9}{|l|}{ Birth cohort } \\
\hline Born 1920-1944 & 0.51 & 0.50 & 0 & 1 & 0.57 & 0.50 & 0 & 1 \\
\hline Born 1945-1959 & 0.49 & 0.50 & 0 & 1 & 0.43 & 0.50 & 0 & 1 \\
\hline Log. HH income & 9.95 & 1.34 & 1.73 & 13.86 & 10.18 & 1.24 & 1.73 & 13.86 \\
\hline Years of Education & 10.04 & 4.49 & 0 & 25 & 10.88 & 4.87 & 0 & 25 \\
\hline Employed & 0.17 & 0.38 & 0 & 1 & 0.18 & 0.38 & 0 & 1 \\
\hline Owner & 0.72 & 0.45 & 0 & 1 & 0.78 & 0.42 & 0 & 1 \\
\hline Married & 0.66 & 0.47 & 0 & 1 & 0.85 & 0.36 & 0 & 1 \\
\hline
\end{tabular}

Source: Own calculations using SHARE waves $4-5$ and SHARELIFE. 
Figure A.1 Predicted values of the health outcomes according to number of children for men in different regions
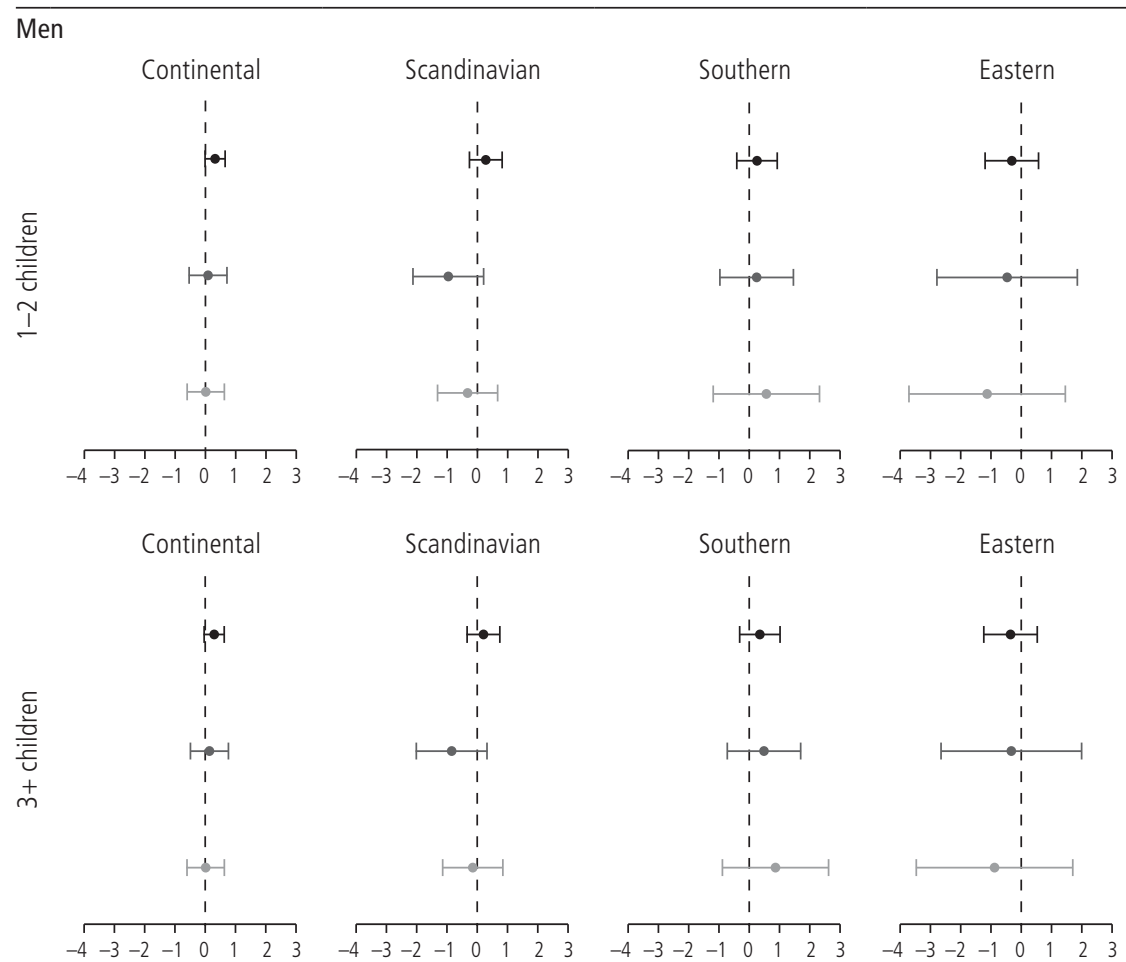

- Chronic - Subjective health - Depression

Notes: Regression models include all variables as presented in Table 1.

Source: Own calculations using SHARE waves $4-5$ and SHARELIFE. 
Figure A.2 Predicted values of the health outcomes according to number of children for women in different regions

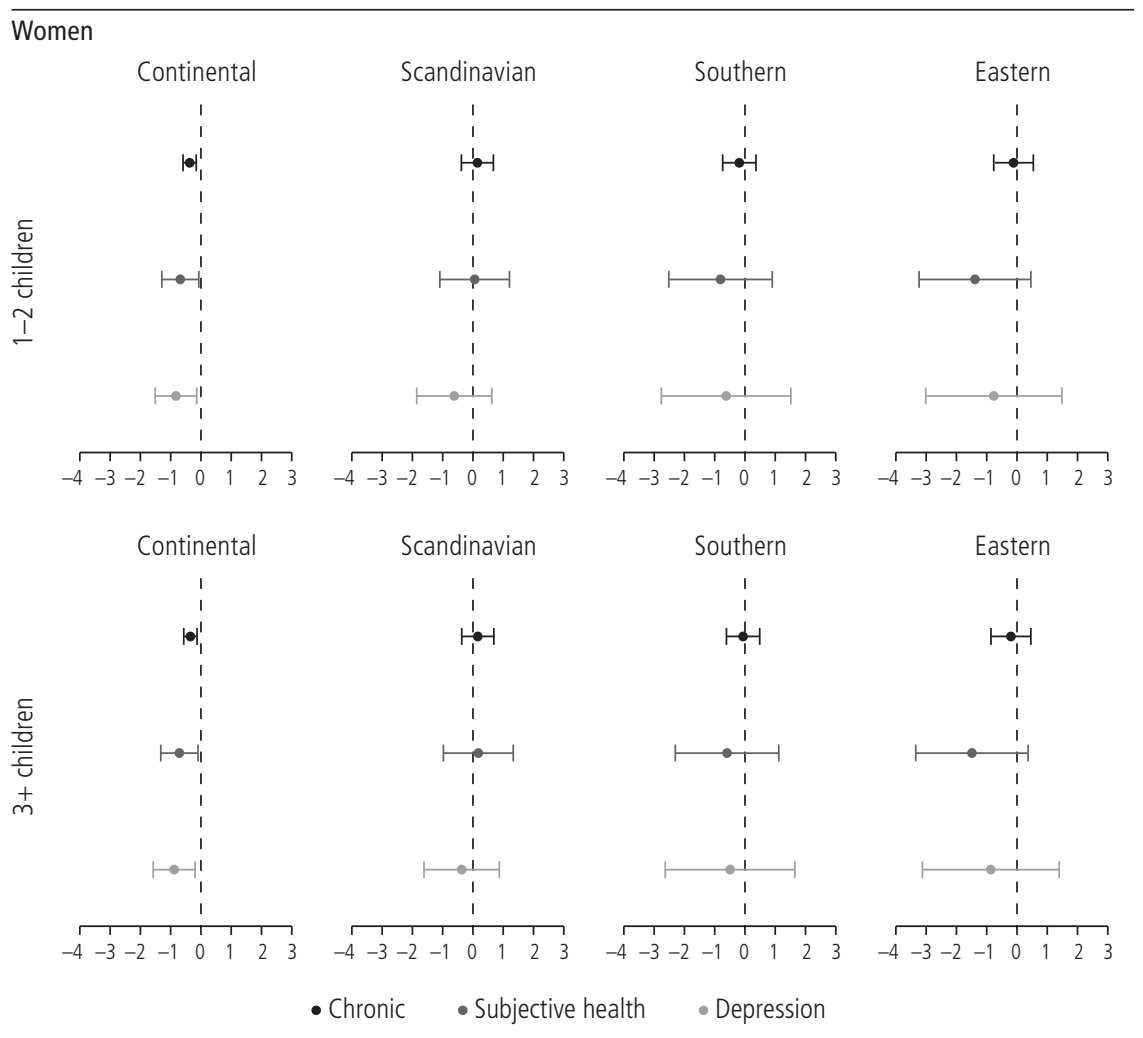

Notes: Regression models include all variables as presented in Table 1.

Source: Own calculations using SHARE waves 4-5 and SHARELIFE.

\begin{tabular}{l|rccc|cccc}
\hline Variables & \multicolumn{4}{|c|}{ Women } & \multicolumn{4}{c}{ Men } \\
& Mean & $\begin{array}{c}\text { Standard } \\
\text { Deviation }\end{array}$ & Minimum Maximum & Mean & $\begin{array}{c}\text { Standard Minimum Maximum } \\
\text { Deviation }\end{array}$ \\
\hline Owner & 0.72 & 0.45 & 0 & 1 & 0.78 & 0.42 & 0 & 1 \\
Married & 0.66 & 0.47 & 0 & 1 & 0.85 & 0.36 & 0 & 1 \\
\hline
\end{tabular}

Source: Own calculations using SHARE waves $4-5$ and SHARELIFE. 
Table A.2 Regressions of fertility history on later life health outcomes for women and men aged 50 and above (coefficients for self-rated health and depression, marginal effects for chronic conditions) with interaction effects of age in groups and number of children

\begin{tabular}{|c|c|c|c|c|c|c|}
\hline \multirow[t]{2}{*}{ Variables } & \multicolumn{3}{|c|}{ Women } & \multicolumn{3}{|c|}{ Men } \\
\hline & $\begin{array}{l}\text { Chronic } \\
\text { conditions }\end{array}$ & $\begin{array}{l}\text { Self-rated } \\
\text { health }\end{array}$ & Depression & $\begin{array}{l}\text { Chronic } \\
\text { conditions }\end{array}$ & $\begin{array}{l}\text { Self-rated } \\
\text { health }\end{array}$ & Depression \\
\hline \multicolumn{7}{|l|}{$\begin{array}{l}\text { Age groups } \\
\text { (RC: Age 50-64) }\end{array}$} \\
\hline $\begin{array}{l}\text { Age } 65-79 \\
\text { Age } 80-91\end{array}$ & $\begin{array}{l}0.928 \\
(0.498) \\
1.589^{* * *} \\
(0.457)\end{array}$ & $\begin{array}{l}0.968 \\
(0.627) \\
1.843^{* *} \\
(0.562)\end{array}$ & $\begin{array}{c}1.836^{*} \\
(0.750) \\
2.645^{* * *} \\
(0.706)\end{array}$ & $\begin{array}{c}0.040 \\
(0.464) \\
-0.248 \\
(0.523)\end{array}$ & $\begin{array}{c}0.922 \\
(0.595) \\
0.088 \\
(0.615)\end{array}$ & $\begin{array}{c}-0.141 \\
(0.609) \\
-0.301 \\
(0.668)\end{array}$ \\
\hline $\begin{array}{l}\text { Number of children } \\
\text { (RC: No children) }\end{array}$ & ref. & ref. & ref. & ref. & ref. & ref. \\
\hline $\begin{array}{l}\text { 1-2 children } \\
3+\text { children }\end{array}$ & $\begin{array}{c}0.236 \\
(0.400) \\
0.291 \\
(0.402)\end{array}$ & $\begin{array}{c}0.114 \\
(0.402) \\
0.212 \\
(0.405)\end{array}$ & $\begin{array}{c}0.610 \\
(0.525) \\
0.774 \\
(0.528)\end{array}$ & $\begin{array}{c}0.132 \\
(0.293) \\
0.118 \\
(0.296)\end{array}$ & $\begin{array}{c}-0.005 \\
(0.349) \\
0.060 \\
(0.353)\end{array}$ & $\begin{array}{c}-0.295 \\
(0.374) \\
-0.156 \\
(0.378)\end{array}$ \\
\hline \multicolumn{7}{|l|}{ Interaction effects } \\
\hline $1-2$ children * Age 65-79 & $\begin{array}{c}-0.482 \\
(0.500)\end{array}$ & $\begin{array}{c}-0.661 \\
(0.630)\end{array}$ & $\begin{array}{c}-1.667^{*} \\
(0.753)\end{array}$ & $\begin{array}{c}0.235 \\
(0.467)\end{array}$ & $\begin{array}{c}-0.793 \\
(0.599)\end{array}$ & $\begin{array}{c}0.279 \\
(0.613)\end{array}$ \\
\hline $1-2$ children * Age 80-91 & $\begin{array}{c}-0.808 \\
(0.461)\end{array}$ & $\begin{array}{c}-0.785 \\
(0.568)\end{array}$ & $\begin{array}{c}-1.917^{* *} \\
(0.713)\end{array}$ & $\begin{array}{c}0.835 \\
(0.528)\end{array}$ & $\begin{array}{c}0.864 \\
(0.625)\end{array}$ & $\begin{array}{r}1.185^{+} \\
(0.677)\end{array}$ \\
\hline $3+$ children * Age 65-79 & $\begin{array}{c}-0.524 \\
(0.502)\end{array}$ & $\begin{array}{c}-0.766 \\
(0.632)\end{array}$ & $\begin{array}{c}-1.797^{*} \\
(0.756)\end{array}$ & $\begin{array}{c}0.231 \\
(0.469)\end{array}$ & $\begin{array}{c}-0.762 \\
(0.602)\end{array}$ & $\begin{array}{c}0.224 \\
(0.616)\end{array}$ \\
\hline $3+$ children * Age 80-91 & $\begin{array}{c}-0.861 \\
(0.464)\end{array}$ & $\begin{array}{c}-0.930 \\
(0.572)\end{array}$ & $\begin{array}{l}-2.174^{* *} \\
(0.718)\end{array}$ & $\begin{array}{c}0.767 \\
(0.530)\end{array}$ & $\begin{array}{c}0.807 \\
(0.627)\end{array}$ & $\begin{array}{l}1.078 \\
(0.680)\end{array}$ \\
\hline Age at $1^{\text {st }}$ Child & $\begin{array}{l}-0.121^{* * *} \\
(0.031)\end{array}$ & $\begin{array}{l}-0.219^{* * *} \\
(0.042)\end{array}$ & $\begin{array}{l}-0.209^{* * *} \\
(0.050)\end{array}$ & $\begin{array}{l}-0.094^{* * *} \\
(0.027)\end{array}$ & $\begin{array}{c}-0.104^{* *} \\
(0.039)\end{array}$ & $\begin{array}{l}-0.178^{* * *} \\
(0.040)\end{array}$ \\
\hline Age at $1^{\text {st }}$ Child squared & $\begin{array}{l}0.002^{* * *} \\
(0.001)\end{array}$ & $\begin{array}{l}0.004^{* * *} \\
(0.001)\end{array}$ & $\begin{array}{l}0.003^{* * *} \\
(0.001)\end{array}$ & $\begin{array}{l}0.001^{* *} \\
(0.000)\end{array}$ & $\begin{array}{l}0.002^{* *} \\
(0.001)\end{array}$ & $\begin{array}{l}0.003^{* * *} \\
(0.001)\end{array}$ \\
\hline \multicolumn{7}{|c|}{ Further regression output omitted } \\
\hline $\mathrm{N}$ & 6242 & 6242 & 6242 & 5577 & 5577 & 5577 \\
\hline R squared & & & 0.113 & & & 0.077 \\
\hline Adjusted R squared & & & 0.109 & & & 0.072 \\
\hline
\end{tabular}

Notes: Standard errors in parentheses; ${ }^{* * *} p \leq 0.001,{ }^{* *} p \leq 0.01,{ }^{*} p \leq 0.05$; including all control variables as in main regressions (Table 1); model specification varies by the metric of the outcome variable: chronic conditions: negative binomial (marginal effects reported), self-rated health: ordered logit; depression scale: OLS; higher values indicate worse health.

Source: Own calculations using SHARE waves $4-5$ and SHARELIFE. 
www.editions-seismo.ch info@editions-seismo.ch

\section{Seismo}

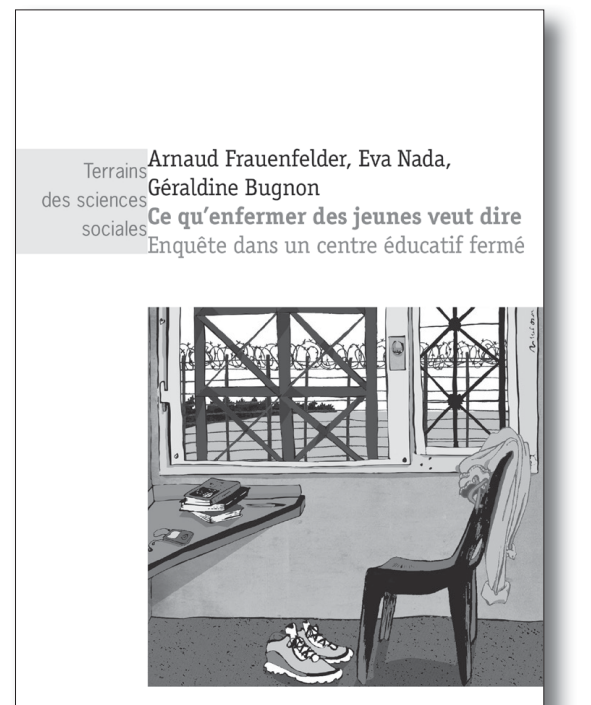

Seismo

\section{Arnaud Frauenfelder}

Eva Nada

Géraldine Bugnon

Ce qu'enfermer des

jeunes veut dire

\section{Enquête dans un centre éducatif fermé}

240 pages, SFr. 32.-

ports de l'institution à l'environnement extérieur. Il s'attache ainsi à saisir les formes de recomposition de l'économie morale de l'enfermement des jeunes. Cette analyse sociologique de la justice pénale des mineur.e.s «par le bas» souligne combien les pratiques de l'État, dans cet univers particulier, s'expriment d'abord par le travail de ses agents.

Arnaud Frauenfelder, sociologue, est professeur ordinaire à la Haute école de travail social, HETS

(HES-SO/Genève) et responsable du Centre de recherche sociale (CERES).

Eva Nada, doctorante en sociologie, est adjointe scientifique à la Haute école de travail social, HETS (HES-SO/Genève) et chercheuse associée à l'Institut de sociologie (UNINE).

Géraldine Bugnon, docteure en sociologie, est adjointe scientifique à la Haute école de travail social, HETS (HES-SO/Genève), chercheuse associée au Centre romand de recherche en criminologie (UNINE) et à l'Institut de recherches sociologiques (UNIGE). 


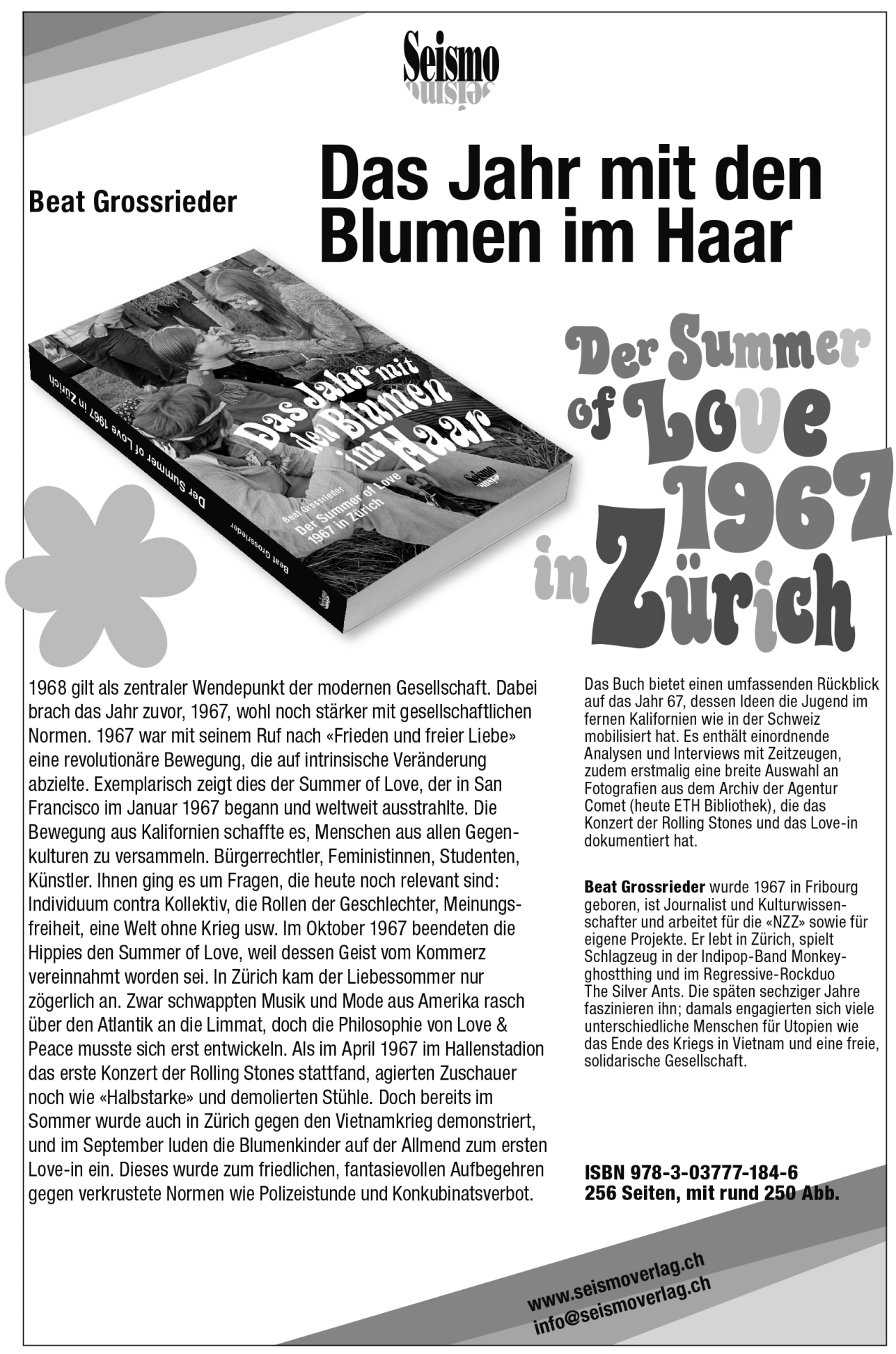

